\title{
Experimental Study of Forced- Convection from Horizontal Rectangular Fins Array into Air Duct
}

\author{
Saad Najeeb Shehab \\ Department of Mechanical Engineering / College of Engineering/Mustansiriyah University/ Baghdad \\ Email: saadnajeeb16@ uomustansiriyah.edu.iq
}

(Received 24 April 2018; accepted 23 July 2018)

https://doi.org/10.22153/kej.2019.07.001

\begin{abstract}
In this work, an experimental study has been done to expect the heat characteristics and performance of the forced-convection from a heated horizontal rectangular fins array to air inside a rectangular cross-section duct. Three several configurations of rectangular fins array have been employed. One configuration without notches and perforations (solid) and two configurations with combination of rectangular-notches and circular-perforations for two various area removal percentages from fins namely $18 \%$ notches-9\% perforations and $9 \%$ notches- $18 \%$ perforations are utilized. The rectangular fins dimensions and fins number are kept constant. The fins array is heated electrically from the base plate with five different magnitudes of power-inputs. Five several air flow velocity into a duct are utilized. The influence of fin geometry, air flow velocity, Reynolds number and the surface heat flux on the heat-performance of forced heat convection have been simulated and studied experimentally. The experimental data indicates that the combination of $18 \%$ rectangular-notched and $9 \%$ circular-perforated rectangular fins array gave best forced heat performance in terms of average heat transfer coefficient about $(25 \%$ $45 \%)$ and $(7 \%-20 \%)$ compared than solid and $9 \%$ notches with $18 \%$ perforations fins array respectively. Five empirical correlations to predict the average Nusselt number for the $18 \%$ notches with $9 \%$ perforations rectangular fins array at wide range of surface heat flux are deduced. The present data are compared with previous works and a good closeness in behavior is noticed.
\end{abstract}

Keywords: Fins array, circular-perforations, rectangular-notches, forced-convection, experimental study.

\section{Introduction}

The heat characteristics and performance enhancement is a very importance subject of thermal-engineering. In general, the heat transfer from heated surfaces are enhanced by increasing the coefficient of convection heat transfer between a heated surface and it's ambient or by fins and fins array to increase the surface area of heat transfer or by both methods. The convection heat dissipation occurs in a several engineering and industrial applications. The importance applications are cooling of electronic and microelectronic components, high power chips, transformers, electrical motors, solar collectors, systems of energy storage.
Toh and Ong [1] introduced an experimental investigation of forced heat convection from vertically fins array through a narrow duct with different air velocities. They suggested an empirical equation as a function of geometrical fin parameters and air velocities. Barhatte et al. [2] experimentally and numerically investigated and analyzed the natural heat convection over a rectangular fins array with and without notches. They utilized different notches types namely, rectangular, triangular and trapezoidal and multi heat inputs with constant dimensions of fins. They utilized the commercially available of fluent software version (6.3) to simulate the heat transfer from fins array to air ambient. They noted that more heat rate is transferred from triangular-notches fins array and found a very good agreement between experimental and 
numerical results. Hossain et al. [3] experimentally investigated the natural and forced heat performance from an aluminum pinfin arrays. They utilized seven pin fins with constant diameter of $8.2 \mathrm{~mm}$ and constant length of $70 \mathrm{~mm}$ was distributed in-line and various air flow rate. They concluded the forced convection heat transfer coefficient $43 \%$ greater than that free convection and they found the pin-fins increases the pumping power. Dhanawade et al. [4] experimentally studied the enhancement of forced convection heat transfer over a horizontal flat plate with three types of rectangular-fins array namely solid, square perforation and circular perforation. They used several sizes of perforations and different values of Reynolds number. They noted the size of perforation and Reynolds number has a larger effect on values of Nusselt number for both perforations type. Also, they observed the percentage of enhancement of the squareperforated fins array is more than that of fins array with circulated-perforated. Sivasubramaniyam [5] achieved an experimental investigation for forced circular pin-fins array with multi fin spacing and two different distributions like in-line and staggered in both directions of stream-wise and span-wise and different rate of air flow. He observed the heat transfer rate is larger in staggered distribution of fins with that of fins in-line distribution. Also, he showed the average convection heat transfer coefficient increases than air flow velocity and Reynolds number increase. Wankhede and Meshram [6] introduced an experimental investigation for free and forced-heat convection over a rectangular fins-array with and without inverted-notches in a horizontal position. The effects of fin spacing, surface heat flux, percentage of notched area and air-flow velocity on the characteristics and performance of convection heat dissipation were studied. They studied the influence of the inverted-notches on single-chimney flow pattern. They illustrated that the coefficient of convection heat transfer increases as percentage of notched area increases about $25 \%$ to $75 \%$ for cases of inverted notches fins array than that cases of fins array without inverted notches in natural and forced-heat convection. Baqir et al. [7] experimentally studied the enhancement heat transfer and reduction of friction factor from staggered perforated pins fins array into a rectangular duct for wide range of Reynolds number. They are studied three types of pin fins, solid, horizontal-vertical perforations and horizontal-vertical-lateral perforations. They concluded the Nusselt number of pin fins includes horizontal-vertical perforations are $11 \%$ larger than those of solid pins and with horizontal-vertical-lateral perforations pins are $21 \%$ greater than those of solid pin fins. Mousa [8] presented an investigation of air flow characteristics and forced heat convection around different extended surfaces shapes like triangular, rectangular and wavy. He found the turbulence intensity of rectangular-extended greater than that of triangular and wavyextended for same dimensions. Mane S.N. and Mane S.S. [9] presented a review on enhancement of forced heat convection from a several configurations of the notches fins array like rectangular, circular, triangular, and trapezoidal. They concluded that more heat transfer is from triangular-notches fins array than that other configuration of notches fins array. Also, they noted the size of notch is very effects on heat transfer enhancement. Shehab [10] experimentally simulated convection heat transfer over rectangular and $\mathrm{V}$-fins array. $\mathrm{He}$ illustrated that the V-fins array gave better heat performance about 20\% larger than rectangular fins array. Shehab [11] experimentally studied the natural heat convection over rectangular fins arrays on a horizontal heated aluminum baseplate to ambient air with and without rectangular-notches portions influence. $\mathrm{He}$ investigated multi parameters such as fins number, percentage of notch area from a fin and surface heat flux on the coefficient of convection heat transfer and Nusselt number. $\mathrm{He}$ observed that the heat convection performance for notch-fins array as coefficient of heat convection is $28 \%$ to $40 \%$ larger with solid-fins array. Mageswaran et al. [12] experimentally investigated the forced convection over perforated square pin fins array with staggered distribution inside a duct. They used five different numbers of perforations and three different diameters of perforations for pin fin. They concluded that the number and diameter of perforations effects on convection heat performance. Also, they found the best heat performance at the optimum perforated diameter (4 mm) and perforated number (3).

The aim of present work is to introduce an experimental study for the forced heat convection over a heated horizontal rectangular fins array to ambient into a rectangular crosssection air duct with nozzle-diffuser ends utilizing three different configurations of 
rectangular-fins arrays, one configuration is solid and two configurations with combination of rectangular-notches and circular-perforations for different area removal percentages from fin. Also, the enhancement of forced heat convection using combination of notched and perforated fins. The influence of air flow velocity and surface heat flux are taken into consideration and studied.

\section{Experimental Test-Rig}

The experimental test-rig is designed and fabricated to cover the tests of present work as shown schematically and photographically in Figures (1a to 1c). It consists of air duct, rectangular fins array, air fan, digital voltage regulator and instruments of measurement namely, digital voltage-current reader, metal vane anemometer model (YK-80AM) to measure the inlet velocity of air flow in a duct, twelve-channels data logger thermometer and K-type of thermocouples wires.

The rectangular fins array is manufactured from bright rolled aluminum plate as one piece with base-plate by CNC machine with dimensions of $(130 \mathrm{~mm}$ length $\times 130 \mathrm{~mm}$ width $\times 3 \mathrm{~mm}$ thickness of base plate). It is electrically heated from a lower surface of base-plate using electrical heater wire is coiled around a thin sheet of mica and then is putted between two layers of mica have same dimensions of baseplat with thickness of $0.4 \mathrm{~mm}$ to obtain an homogenous heating of fins array base-plate and ensured the complete insulated of electrical heater.

The dimensions of rectangular fins are (130 $\mathrm{mm}$ length $\times 26 \mathrm{~mm}$ height $\times 3 \mathrm{~mm}$ thickness). The fins array is housed in a $130 \mathrm{~mm}$ length $\times$ $130 \mathrm{~mm}$ width $\times 4.5 \mathrm{~mm}$ depth rectangular-hole milled on the upper surface of thermo-stone's slab $(200 \mathrm{~mm}$ length $\times 200 \mathrm{~mm}$ width $\times 100$ $\mathrm{mm}$ thickness) to obtain a best thermal insulation and minimize the heat conduction losses from sides and lower of base-plate of fins array.

The whole assembly is placed in a halfway of rectangular cross-section air duct with nozzle-diffuser ends. The air duct is manufactured from wood with thickness of 15 $\mathrm{mm}$ and it's of $1000 \mathrm{~mm}$ long with an internal width $(w)$ of $230 \mathrm{~mm}$ and internal height $(b)$ of $100 \mathrm{~mm}$, and the total length of duct with nozzle and diffuser ends is $1750 \mathrm{~mm}$. The front face of air duct is made of $6 \mathrm{~mm}$ thickness clear acrylic sheet. Multi-velocities air fan is fitted at the diffuser end of duct to provide a forced heat convection condition.

The surface temperatures of the fins array are measured using five type-K calibrated thermocouples are fixed at various suitable positions in the lower surface of base-plate (four in corners and one in the center of base-plate). Another three same thermocouples are utilized to measure the temperatures difference at lower and sides of fins array base-plate to evaluate the heat conduction losses through a thermo-stone's slab as shown in Figure (2). Plus two thermocouples to record the inlet and outlet air temperatures inside a duct.

The conditions of steady state for all tests of present work are attained from 45 to 90 minutes depending on the electrical power input. The readings of thermocouples have been recorded when the temperatures difference between two readings is $\pm \leq 0.5{ }^{\circ} \mathrm{C}$ within ten minutes approximately. Then, the surface temperatures of base-plate of fins array, air temperature into air duct, the voltage, and the current intensity passed to electrical wire heater are registered.

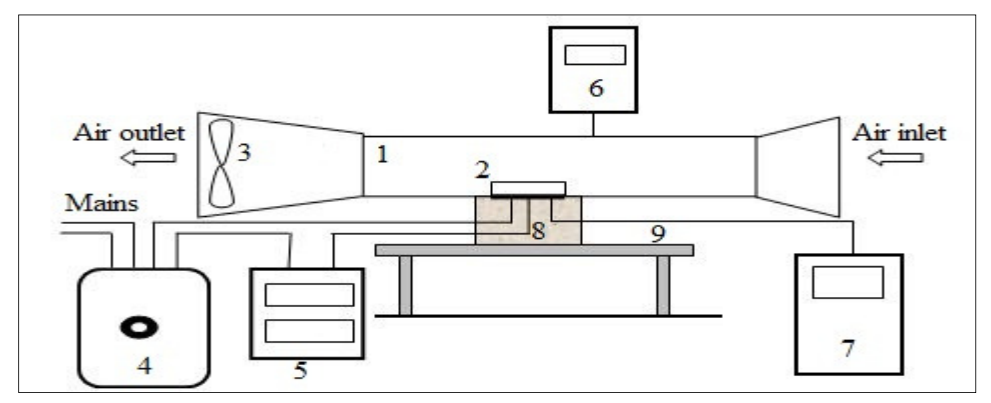

a. Sketch of an experimental test-rig. 


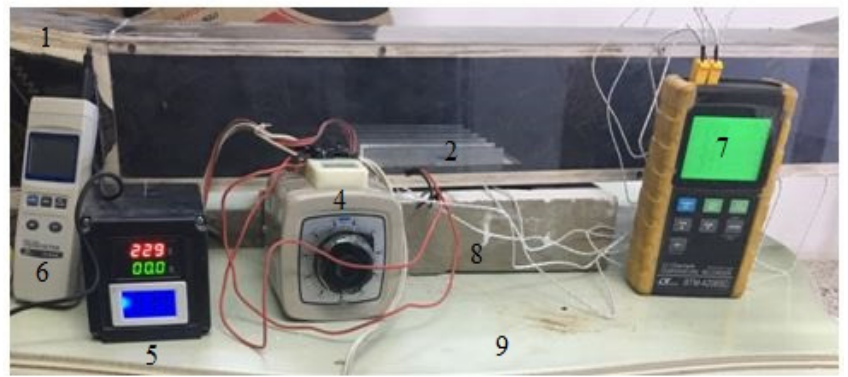

b. Photograph of an experimental test-rig.

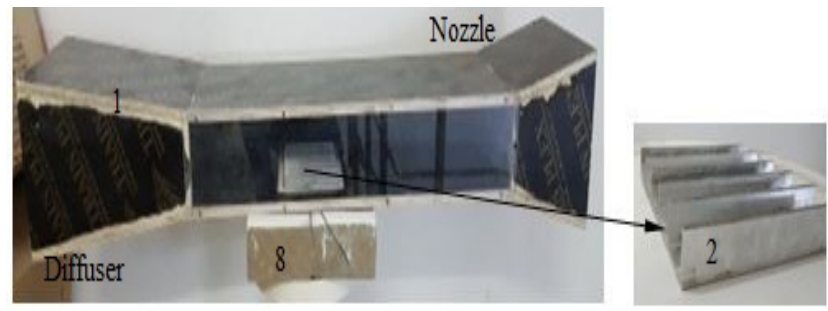

c. Photograph of an air duct.

1. Air duct 2. Rectangular fins array 3. Air fan 4. Digital Voltage regulator 5. Digital voltage-current reader 6. Metal vane anemometer 7. Twelve-channels data logger thermometer 8. Thermo-stone's slab 9. Flat table.

Fig. 1. Experimental test-rig.

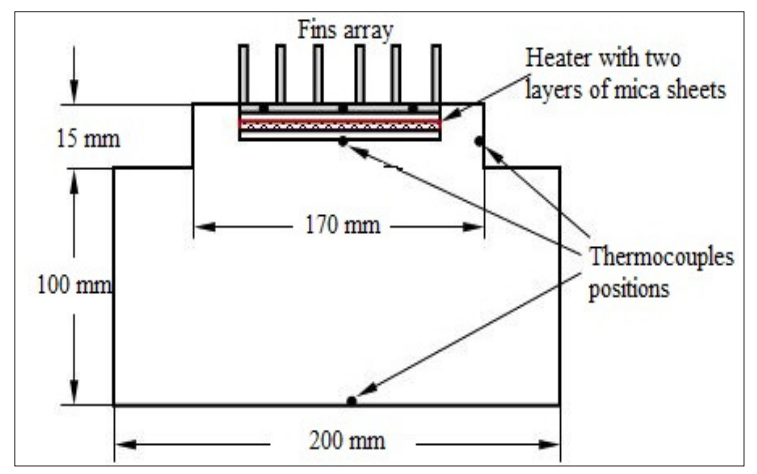

Fig. 2. Schematic diagram of fins array assembly with thermocouples positions.

\section{Calculation Procedures}

The present work is carried out for three different configurations of rectangular fins arrays namely, solid, with combination of $18 \%$ rectangular-notch and 9\% circular-perforations and with combination of $9 \%$ rectangular-notch and $18 \%$ circular-perforations as shown in Figure (3). The rectangular fin dimensions are fin length $(L)=130 \mathrm{~mm}$, fin height $(H)=26 \mathrm{~mm}$ and fin thickness $(t)=3 \mathrm{~mm}$ and fins number $(N)=6$ are kept constant for all configurations of fins array. Table (1) illustrate the dimensions of fins arrays utilized. Five different of surface heat fluxes $(q)$ values namely, 1479, 2958, 4437, 5917 and $7396 \mathrm{~W} / \mathrm{m}^{2}$ are utilized.

The electrical power input $\left(Q_{i}\right)$ to the wire heater is evaluted as a product of voltage $(V)$, current $(I)$ :

$Q_{i}=V I$

It is transformed to heat energy and it transferred from a rectangular fins array to ambient air inside the duct by forced heat convection $\left(Q_{c v}\right)$ plus heat losses due to heat radiation $\left(Q_{r}\right)$ and heat conduction $\left(Q_{c d}\right)$ lower and besides fins array. Hence,

$Q_{i}=Q_{c v}+Q_{r}+Q_{c d}$

The loss of heat radiation between surfaces of polished rolled aluminum fins array with emissivity of $\varepsilon=0.05$ and the air temperature inside a duct $\left(T_{\infty}\right)$ is computed from StefanBoltzmann law. The losses of heat conduction $\left(Q_{c d}\right)$ from lower and sides of fins array baseplate across thermo-stone's slab (200 mm length $\times 200 \mathrm{~mm}$ width $\times 100 \mathrm{~mm}$ thickness) with thermal conductivity of $k_{t}=0.15 \mathrm{~W} / \mathrm{m} . \mathrm{K}$ are calculated using Fourier's law [13, 14].

Then, the forced-convection heat transfer $\left(Q_{c v}\right)$ can be evaluted as follows:

$Q_{c v}=V I-\left(Q_{r}+Q_{c d}\right)$

Also, it is can be evaluted from Newton's equation of cooling as $[13,14]$ :

$Q_{c v}=h_{a v} A_{s}\left(T_{s a v}-T_{\infty}\right)$ 
The average forced-convection heat transfer coefficient $\left(h_{a v}\right)$ can be evaluted as:

$h_{a v}=\frac{V I-\left(Q_{r}+Q_{c d}\right)}{A_{s}\left(T_{s a v}-T_{\infty}\right)}$

$T_{\infty}=\left(T_{i}+T_{o}\right) / 2$

$T_{\text {sav }}=\frac{\sum_{i=1}^{p} T_{s i}}{p}$

where, $T_{i}$ and $T_{o}$ are the inlet and outlet air temperatures respectively, $T_{s}$ is the local surface temperature.

$A_{s}$ is the surface area of rectangular fins array, and it computed as follows:

- Solid rectangular fins array,

$A_{s}=\left(L^{2}-N t L\right)+2 N H L$

- Combination of rectangular-notches and circular-perforations rectangular fins array,

$A_{s}=\left(L^{2}-N t L\right)+2 N\left[H L-\left(A_{n}+n A_{p}\right)\right]$

where,

$L$ is the fin length (base-plate side), $N$ is the fins number, $t$ is the fin thickness, $H$ is the fin height, $\mathrm{n}$ is the perforations number in one fin, $A_{n}$ is the notch area and $A_{p}$ is the perforation area,

$A_{n}=L_{n} H_{n}$

$A_{p}=\frac{\pi}{4} d^{2}$

The average Nusselt number $\left(N u_{a v}\right)$ based on the hydraulic diameter of the air duct $\left(D_{h}\right)$ as characteristics length can be calculated as [4, 15]:

$$
N u_{a v}=\frac{h_{a v} D_{h}}{k_{a}}
$$

The Reynolds number $(\mathrm{Re})$ for the flow into a duct can with the hydraulic diameter $\left(D_{h}\right)$ be expressed as [15]:

$R e=\frac{u D_{h}}{v}$

and the hydraulic diameter of rectangular crosssection air duct is [15]:

$D_{h}=\frac{2 w b}{(w+b)}$

where,

$u$ is the velocity of air flow in a duct, $w$ is the internal width of duct and $b$ is the internal height of duct.

The air properties used in experimental calculations are taken at film temperature $\left(T_{f}\right)$. It's an approximation to temperature of the fluid into a convection boundary layer and evaluted as the arithmetic mean of average surface temperature $\left(T_{s a v}\right)$ and ambient air temperature inside a duct $\left(T_{\infty}\right)$ in $(\mathrm{K})$ [15].

The percent error $(\% e)$ is the ratio of absolute error to the actual value, and computed as:

$\% e=\frac{\left|V_{\text {exp }}-V_{\text {cor }}\right|}{V_{\text {exp }}} \times 100$

The mean relative squared-errors (MRSE) is evaluted as:

$M R S E=\left[\frac{1}{j-1} \sum_{i=1}^{j}\left(\frac{V_{\text {exp }}-V_{\text {cor }}}{V_{\text {exp }}}\right)^{2}\right]^{1 / 2}$

where, $\left(V_{\text {exp }}\right)$ and $\left(V_{c o r}\right)$ are experimental and correlated values respectively, $j$ is the data number.
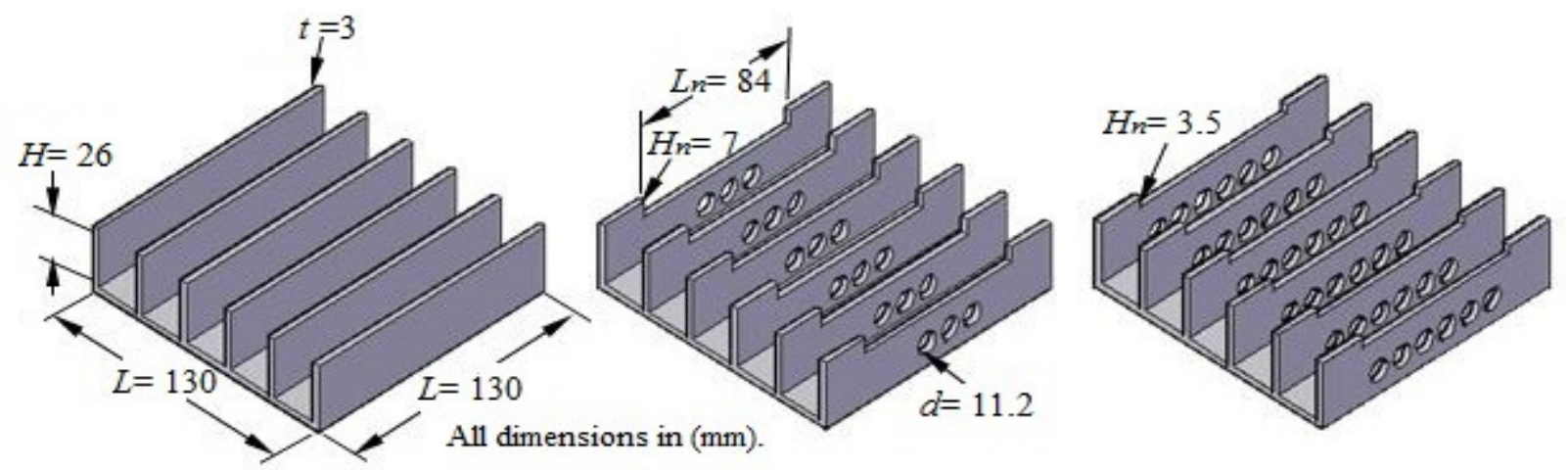

a. solid b. $18 \%$ rectangular-notches with $9 \%$ circular-perforations c. $9 \%$ rectangular-notches with $18 \%$ circular-perforations.

Fig. 3. Configurations of rectangular fins array. 
Table 1,

Dimensions of fins array studied.

\begin{tabular}{lllllc}
\hline $\begin{array}{l}\text { Fins array } \\
\text { Configuration }\end{array}$ & $\begin{array}{l}\text { Rectangular fin } \\
\text { dimensions } \\
(\boldsymbol{L} \times \boldsymbol{H} \times \boldsymbol{t}) \mathbf{~ m m}\end{array}$ & $\begin{array}{l}\text { Fins } \\
\text { numbe } \\
\mathbf{r}\end{array}$ & $\begin{array}{l}\text { Rectangular- } \\
\text { notch dimensions } \\
\left(\boldsymbol{L}_{\boldsymbol{n}} \times \boldsymbol{H}_{\boldsymbol{n}}\right) \mathbf{m m}\end{array}$ & $\begin{array}{l}\text { Circular- } \\
\text { perforations } \\
\text { dimensions }(\boldsymbol{d} \mathbf{m m} \times \boldsymbol{n})\end{array}$ & $\begin{array}{l}\text { Surface } \\
\mathbf{a r e a} \\
\left(\boldsymbol{A}_{\boldsymbol{s}}\right) \mathbf{m}\end{array}$ \\
\hline $\begin{array}{l}\text { Solid } \\
18 \% \text { rectangular } \\
\text { notches-9\% circular }\end{array}$ & $130 \times 26 \times 3$ & 6 & --- & -- & 0.00512 \\
$\begin{array}{l}\text { perforations } \\
9 \% \text { rectangular notches- }\end{array}$ & $130 \times 26 \times 3$ & 6 & $84 \times 7$ & $11.2 \times 3$ & 0.0445 \\
$\begin{array}{l}18 \% \text { circular } \\
\text { perforations }\end{array}$ & & 6 & $84 \times 3.5$ & $11.2 \times 6$ & 0.0445 \\
\hline
\end{tabular}

\section{Results and Discussion}

The present work simulates experimentally effect of the fins configurations (solid, with combination of rectangular-notches and circular-perforations), the percentage of area removal from fin, surface heat flux and the air flow velocity on forced-convection heat performance of a heated horizontal fins array inside air duct.

Figures (4a to 4c) illustrate behavior of the average forced heat convection coefficient versus surface heat flux for different configurations of rectangular fins array and different air velocities $(u)$ ranging from $1.2 \mathrm{~m} / \mathrm{s}$ to $3.6 \mathrm{~m} / \mathrm{s}$. They are clear that the average heat transfer coefficient $\left(h_{a v}\right)$ gradually increases as surface heat flux $(q)$ increases. Also, the average heat-transfer coefficient $\left(h_{a v}\right)$ increases with increasing air flow velocity in the duct. Additionally, values of the average forced heat convection coefficient for $18 \%$ notches with $9 \%$ perforations rectangular fins array are larger about $25 \%$ to $45 \%$ than that solid fins array and larger about $7 \%$ to $20 \%$ than that $9 \%$ notches with $18 \%$ perforations rectangular fins array because of the combination of notches and perforations allow more fresh air comes inwards between fins channels and due to large increases in convection heat transfer coefficient. The notch of fin is removed from a non-effective part near of the stagnation zone of fin, while the perforations help to increase the turbulence of air flow into a duct and this, cause increases in forced-convection heat transfer rate from fins array surfaces.

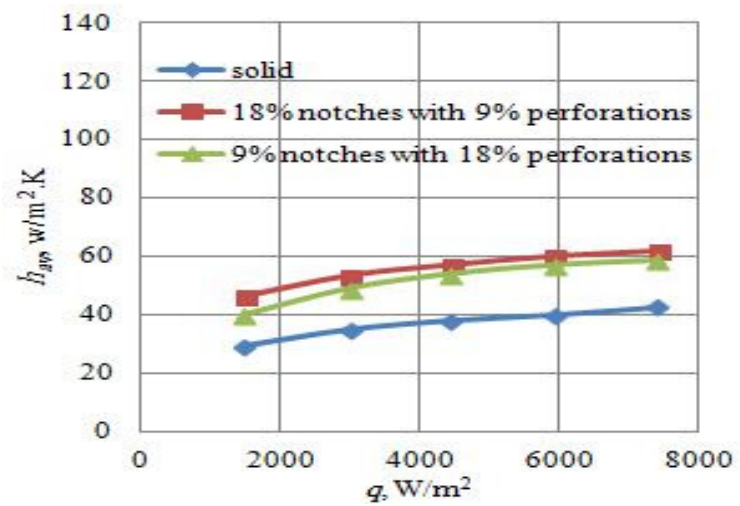

a. Air flow velocity, $u=1.2 \mathrm{~m} / \mathrm{s}$

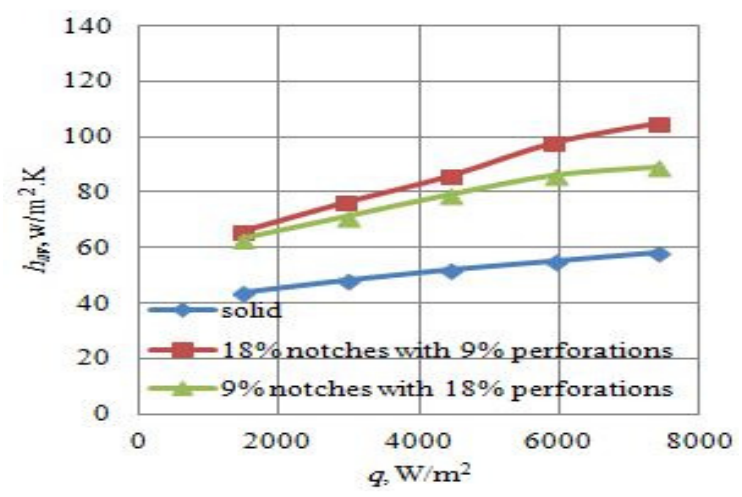

b. Air flow velocity, $u=2.4 \mathrm{~m} / \mathrm{s}$

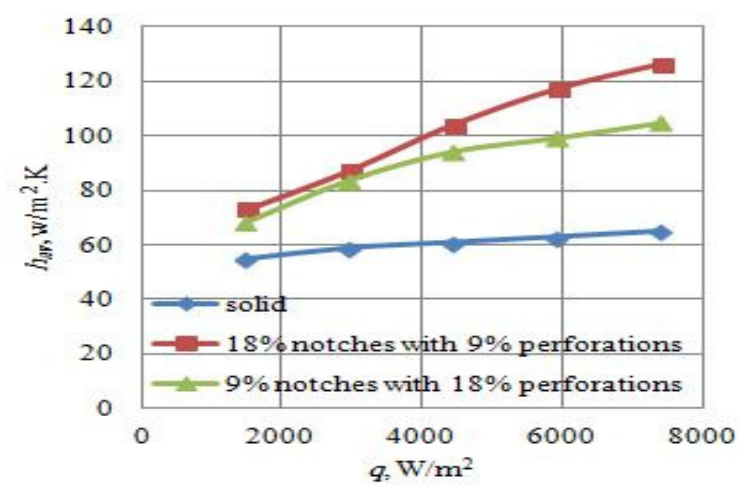

c. Air flow velocity, $u=3.6 \mathrm{~m} / \mathrm{s}$

Fig. 4. Average forced-convection heat transfer coefficient versus surface heat flux for three configurations of rectangular fins array at five different air flow velocities, $(u=1.2,2.4$ and 3.6 $\mathbf{m} / \mathbf{s})$. 


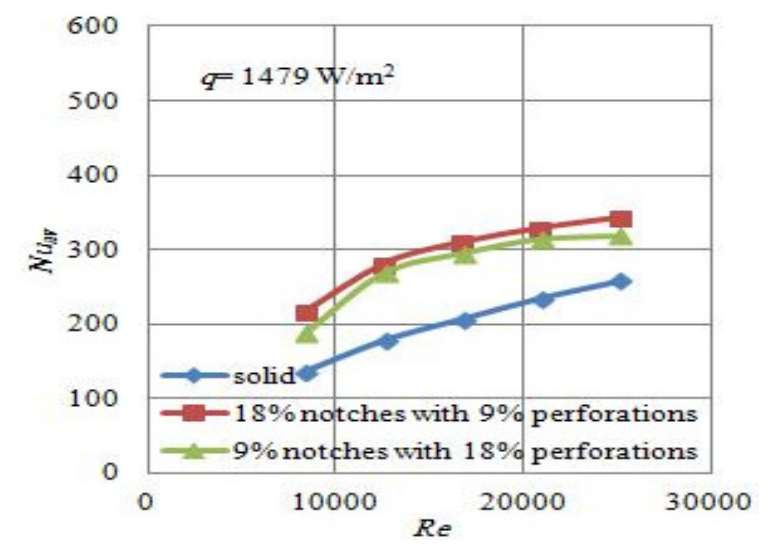

Fig. 5. Average Nusselt number versus Reynolds number for surface heat flux, $q=1479 \mathrm{~W} / \mathrm{m}^{2}$.

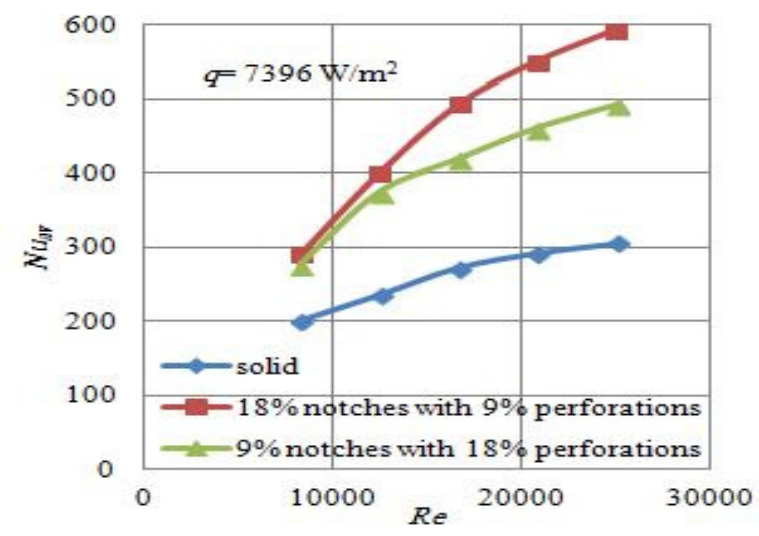

Fig. 6. Average Nusselt number versus Reynolds number for surface heat flux, $q=7396 \mathrm{~W} / \mathrm{m}^{2}$.

Figures (5) and (6) show the behavior of average Nusselt number $\left(N u_{a v}\right)$ against Reynolds number $(R e)$ for solid, $18 \%$ notches with $9 \%$ perforations and $9 \%$ notches with $18 \%$ perforations rectangular fins arrays at surface heat flux, $q=1479$ and $7396 \mathrm{~W} / \mathrm{m}^{2}$. It is observed that the average Nusselt number increases greatly with increasing Reynolds number for all cases studied because the surface temperatures decrease with increasing air flow velocity into a duct. Also it's clear that the average Nusselt number values for $18 \%$ notches with $9 \%$ perforations rectangular fins array are larger than those of solid and 9\% notches with $18 \%$ perforations fins arrays. Hence, the best fins array is $18 \%$ notches with $9 \%$ perforations because the combination of notches and perforations which increases the forcedconvection heat dissipation rate and turbulence of flow into an air duct and allow more cold air enters between fins channels and contacted the fins array hot surfaces. Also, increasing the removed area of non-effective part from $9 \%$ to
$18 \%$ of fins area improves the forcedconvection heat performance. Furthermore, it's observed that the average Nusselt number improves about $15 \%$ to $42 \%$ when the surface heat flux increases because the average heat convection coefficient increases with percent reach about $45 \%$ larger than those solid fins array.

Figure (7) appears five correlations between average Nusselt number and Reynolds number for $18 \%$ notches with $9 \%$ perforations rectangular fins array for a multi-levels of surface heat flux $(q)$ from $1479 \mathrm{~W} / \mathrm{m}^{2}$ to 7396 $\mathrm{W} / \mathrm{m}^{2}$. It is clear that the average Nusselt number increases with increasing Reynolds number. The following five empirical correlations are concluded:

$$
\begin{aligned}
& N u_{a v}=5.3475(R e)^{0.4145} \\
& N u_{a v}=4.2607(R e)^{0.4537} \\
& N u_{a v}=1.9742(R e)^{0.5459} \\
& N u_{a v}=1.1661(R e)^{0.611} \\
& N u_{a v}=0.7885(R e)^{0.6578}
\end{aligned}
$$

Figures $(8 \mathrm{a}$ and $8 \mathrm{~b}$ ) show a comparisons of the correlated average Nusselt numbers $\left(N u_{a v-c o r}\right)$ with those experimental $\left(N u_{a v-\exp }\right)$ for $18 \%$ notches with $9 \%$ perforations rectangular fins array at surface heat fluxes, $q=1479 \mathrm{~W} / \mathrm{m}^{2}$ and $7396 \mathrm{~W} / \mathrm{m}^{2}$ using Eqs. (17) and (21) respectively. They are appear that the percentage error $(e \%)$ of the experimental values situated between $+10 \%$ and $-10 \%$ of correlated values for surface heat fluxes, $q=$ $1479 \mathrm{~W} / \mathrm{m}^{2}$ and between $+12 \%$ and $-10 \%$ of correlated values for surface heat fluxes, $q=$ $7396 \mathrm{~W} / \mathrm{m}^{2}$, and the mean relative squarederrors (MRSE) are 0.145 and 0.187 respectively.

Furthermore, the test is carried out on a smooth air duct using the same base-plate without fins array. Then, the following empirical correlation is concluded:

$N u_{a v}=0.1522(R e)^{0.6775}$

and compared with Dittus and Boelter [1 $\left.{ }^{\circ}\right]$, and Dhanawade et al. [4] correlations:

$N u_{a v}=0.024(R e)^{0.8}(P r)^{0.4}$

$N u_{a v}=0.015(R e)^{0.816}$

This is valid for turbulent flow in a rectangular smooth air duct as shown Figure (9). It can be seen a good similarity in the behavior, but the present results gave values of average Nusselt number higher those done in Dittus and Boelter and Dhanawade et al. correlations because the different in duct dimensions, air flow velocity and surface heat flux levels. 


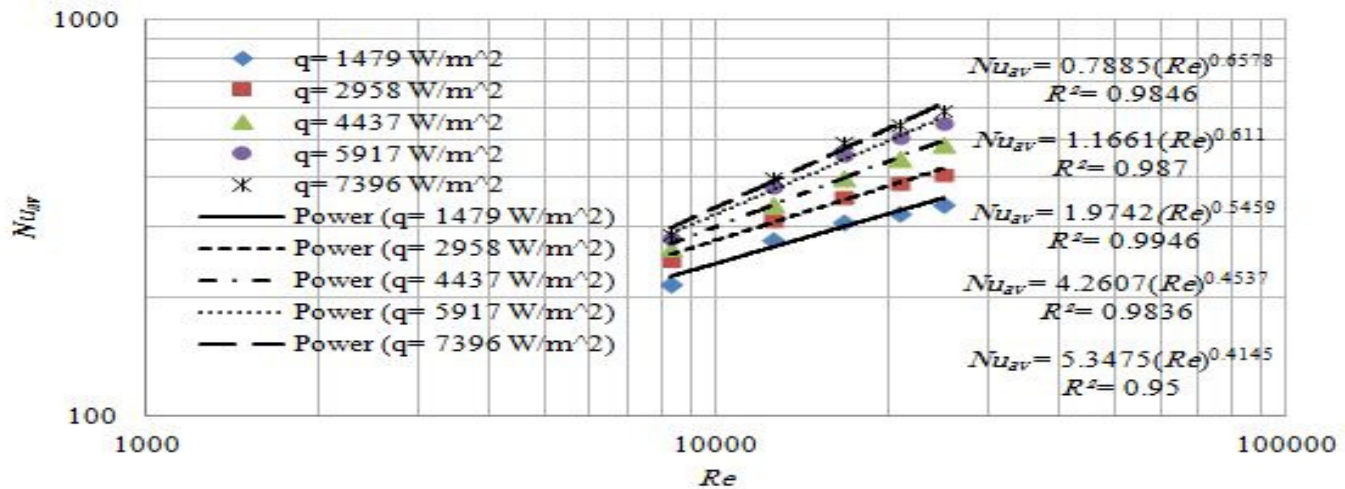

Fig. 7. Analysis of present data for $18 \%$ notches-9\% perforations rectangular fins array with concluded empirical correlations.

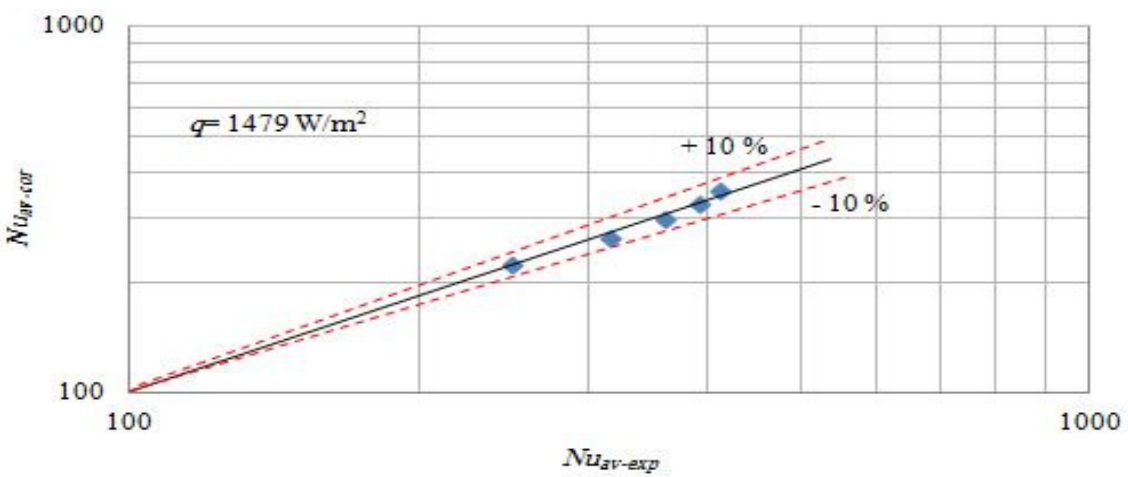

a. Surface heat flux, $q=1479 \mathrm{~W} / \mathrm{m}^{2}$

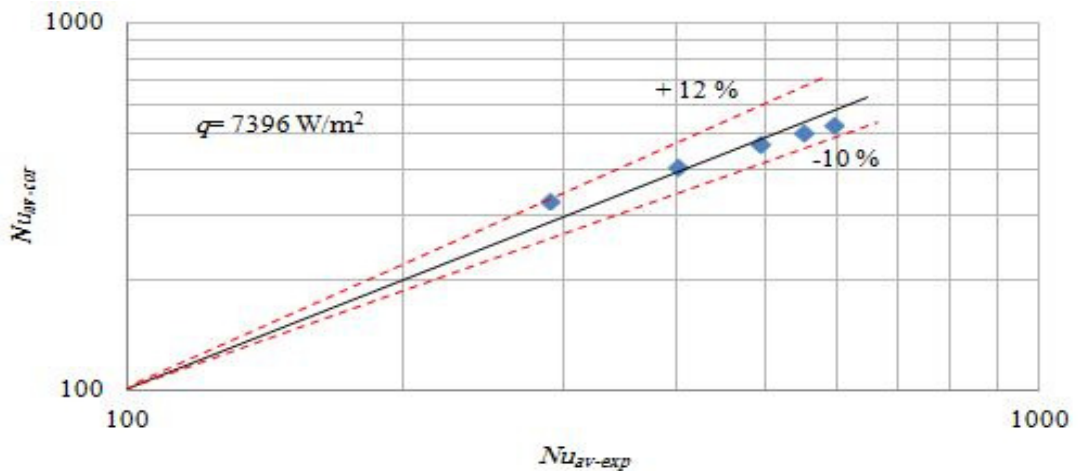

b. Surface heat flux, $q=7396 \mathrm{~W} / \mathrm{m}^{2}$

Fig. 8. Comparison of the correlated average Nusselt numbers $\left(N u_{a v-c o r}\right)$ with those of experimental $\left(N u_{a v-e x p}\right)$ for $18 \%$ notches-9\% perforations rectangular fins array.

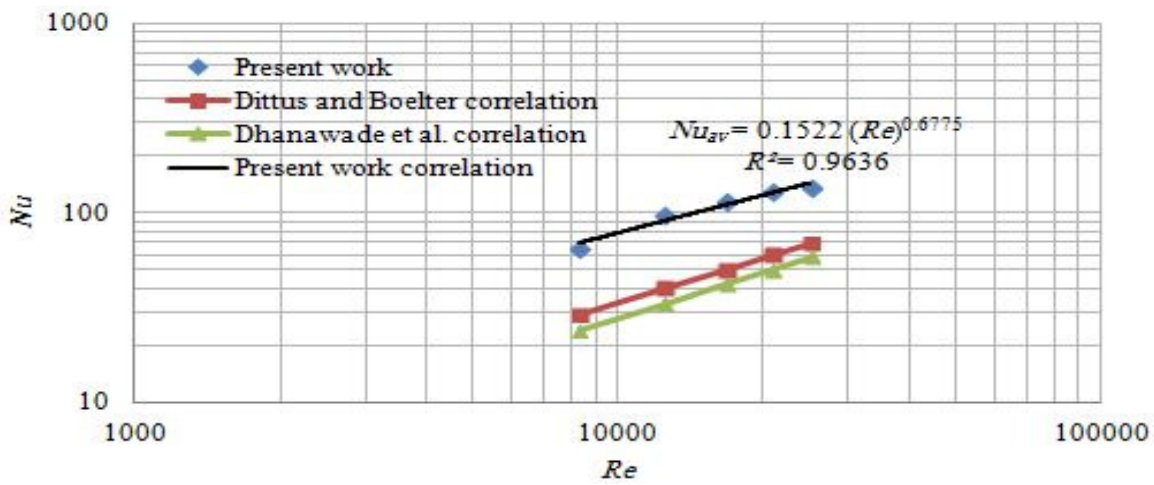

Fig. 9. Comparison of the present work for a smooth duct with Dittus and Boelter $\left[1^{\circ}\right]$ and Dhanawade et al. [4] correlations. 


\section{Conclusions}

The present work has achieved an experimental study of an electrically heated horizontal rectangular fins array inside an air duct subjected to forced-convection. Three configurations of rectangular fins namely, solid, combination of $18 \%$ rectangular-notches with $9 \%$ circular-perforations and combination of $9 \%$ rectangular-notches with $18 \%$ circularperforations are utilized with constant fins number and dimensions. The important conclusions can be drawn:

1. The rectangular fins array includes combination of $18 \%$ notches with $9 \%$ perforations gave best forced heat performance in terms of average heat convection coefficient about ( $25 \%$ to $45 \%$ ) and (7\% to 20\%) larger than those solid and $9 \%$ notches with $18 \%$ perforations fins array respectively.

2. Increasing of the removed area of noneffective part (notches) from $9 \%$ to $18 \%$ of fins area improves the heat characteristics and gave maximum values of average heat transfer coefficient (hav-max $=126 \mathrm{~W} / \mathrm{m} 2$. K) and Nusselt number (Nuav-max=592).

3. The average Nusselt numbers increases strongly from $34 \%$ to $48 \%$ approximately with increases Reynolds numbers for all studied rectangular fins arrays.

4. The average Nusselt number improves clearly about $\% 15$ to $42 \%$ with increasing surface heat flux for all studied cases.

5. Five empirical correlations to predict the average Nusselt number for the 18\% notches with $9 \%$ perforations rectangular fins array at wide range of surface heat flux are concluded.

\section{Nomenclature}

$A_{n} \quad$ notch area, $\left(\mathrm{m}^{2}\right)$

$A_{p} \quad$ Perforation area, $\left(\mathrm{m}^{2}\right)$

$A_{s} \quad$ surface area of heat transfer, $\left(\mathrm{m}^{2}\right)$

$b \quad$ internal height of air duct, (m)

$d$ diameter of perforation, (m)

$D_{h} \quad$ hydraulic diameter of air duct, (m)

$h$ forced-convection heat transfer coefficient, $\left(\mathrm{W} / \mathrm{m}^{2} . \mathrm{K}\right)$

$H$ fin height, (m)

$H_{n} \quad$ notch height, (m)

I input current, (A)

$k_{a} \quad$ thermal conductivity of air, (W/m.K)

$L \quad$ fin height (base-plate side), (m)
$L_{n} \quad$ notch length, (m)

$N$ number of fins

$n \quad$ perforations number

$\mathrm{Nu}$ Nusselt number

$q \quad$ surface heat flux, $\left(\mathrm{W} / \mathrm{m}^{2}\right)$

$Q_{c d} \quad$ loss of heat conduction, (W)

$Q_{c v}$ rate of forced-convection heat transfer, (W)

$Q_{i} \quad$ electrical power input, (W)

$Q_{r} \quad$ loss of heat radiation, (W)

Re Reynolds number

$t \quad$ fin thickness, (m)

$T_{\infty} \quad$ air temperature into a duct, $\left({ }^{\circ} \mathrm{C}\right)$

$T_{f} \quad$ film temperature, $(\mathrm{K})$

$T_{i} \quad$ inlet air temperature, $\left({ }^{\circ} \mathrm{C}\right)$

$T_{o} \quad$ outlet air temperature, $\left({ }^{\circ} \mathrm{C}\right)$

$T_{s} \quad$ surface temperature, $\left({ }^{\circ} \mathrm{C}\right)$

$u \quad$ velocity of air flow, $(\mathrm{m} / \mathrm{s})$

$V \quad$ voltage, $(\mathrm{V})$

$w$ internal width of air duct, (m)

\section{Greek Letters}

$v \quad$ kinematic viscosity, $\left(\mathrm{m}^{2} / \mathrm{s}\right)$

\section{Subscript Symbols}

av average

\section{References}

[1] Toh, K.C. and Ong, Y.K. "Forced Convection Heat Transfer from Vertically Stacked Fin Arrays with a Shrouding Wall ", International Communications in Heat and Mass Transfer Journal, Vol. 19, Issue 3, pp.373-384, 1992.

[2] Barhatte, S.H., Chopade, M.R. and Kapatkar, V. N., "Experimental and Computational Analysis and Optimization for Heat Transfer Through Fins with Different Types of Notch ", Journal of Engineering Research and Studies, V. 2, Issue 1, pp. 133-138, 2011.

[3] Hossain, M. S., Ahamed, J. U., Akter, F., Das, D. and Soha, S. "Heat Transfer Analysis of Pin Fin Array “, Proceedings of the International Conference on Mechanical Engineering and Renewable Energy, Bangladesh, 24-27 December 2013.

[4] Dhanawade, K. H., Sunnapwar, V. K. and Dhanawade, H. S. "Thermal Analysis of Square and Circular Perforated Fin Arrays 
by Forced Convection", International Journal of Current Engineering and Technology, Special Issue-2, pp. 109-114, February 2014.

[5] Sivasubramaniyam, R. "Performance Analysis on Array of Circular Fins through Forced Convection", International Journal of Engineering Research and Technology, Vol. 7, No. 1, pp. 1-8, 2014.

[6] Wankhede, S.D. and Meshram, C.B. "Experimental Study and Investigation of Heat Transfer from Horizontal Rectangular Inverted Notch Fin Arrays (INFAS) under Natural and Forced Convections ", International Journal Researchers, Scientists and Developers, Vol. 2, No. 1, pp. 13-16, 2014.

[7] Baqir, A.S., Qasim, A. and Adnan, A. "Experimental Study for Staggered Perforated Array of Pins Like Fins in a Rectangular Air Cross Flow", The Iraqi Journal for Mechanical and Material Engineering, Vol. 14, No. 2, pp. 261-275, 2014.

[8] Mousa, N. A. "Study on Flow Characteristics and Heat Transfer Behavior around Different Geometrical Corrugated Extended Surfaces", AlKhwarizmi Engineering Journal, Vol. 11, No. 2, pp. 31-44, 2015.

[9] Mane, S.N. and Mane, S.S. "A Review on Heat Transfer from Different Types of Notch Fin Arrays under Forced Convection to Increase Heat Energy
Transfer", International Journal on Recent Technologies in Mechanical and Automobile Engineering, Vol. 2, Issue 6, pp. 15-18, 2015.

[10] Shehab, S.N. Shehab, S.N. "Experimental Simulation of Natural Heat Convection from Finned Vertical Plate with Different Inclinations', Al-Khwarizmi Engineering Journal, Vol. 12, No. 3, pp. 61-71, 2016.

[11] Shehab, S.N. "Experimental Study of Free-Convection from Rectangular Fins Array on a Heated Horizontal Plate with Notch Effects", Al-Nahrain Journal for Engineering Sciences, Vol. 20, No. 1, pp. 140-148, 2017.

[12] Mageswaran, C., Karthikeyan, R. and Muthukumaran, R. "Heat Transfer Enhancement of Perforated Square Pin-Fin Array in a Rectangulr Duc", International Journal for Research in Applied Science and Engineering Technology, Vol. 5, Issue IX, pp. 1826-1832, 2017.

[13] Cengel, Y. A. "Heat Transfer: A Practical Approach", McGraw-Hill Companies, Second Edition, USA, 2008.

[14] Rajput, R.K. "Heat and Mass Transfer", S. Chand and Company LTD., Fifth Revised Edition, India, 2012.

[15] Bejan, A. "Convection Heat Transfer", John Wiley and Sons, Inc., Fourth Edition, USA, 2013. 


\title{
دراسة تجريبية للحمل القسري من مصفوفة زعانف مستطيلة أفقية داخل مجرى هواء
}

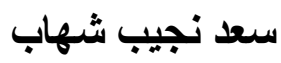 \\ قسم الهنسة الميكانيكية / كلية الهندسة / الجامعة المستنصرية / بغداد \\ البريد اللكتروني: uomustansiriyah.edu.iq
}

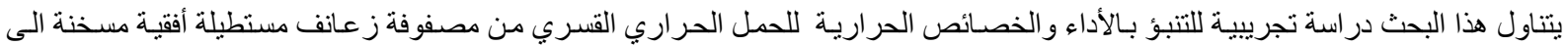

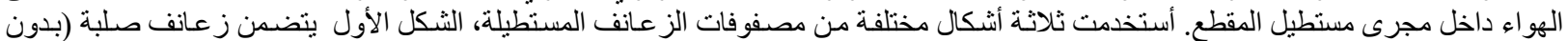

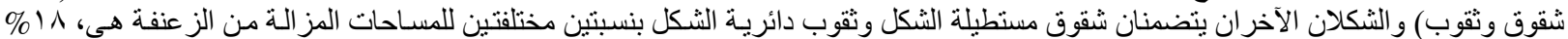

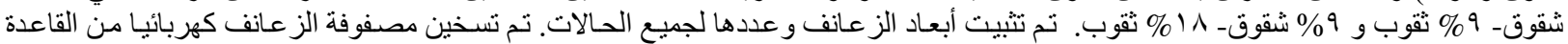

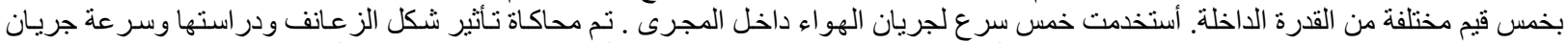

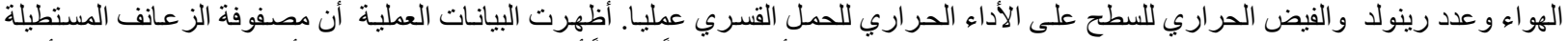

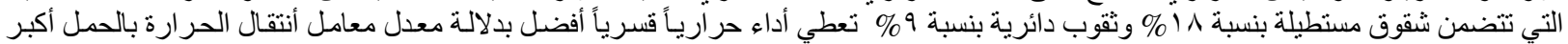

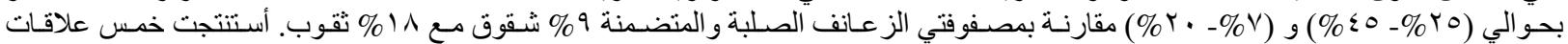

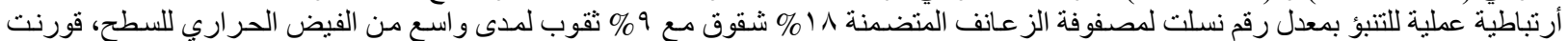

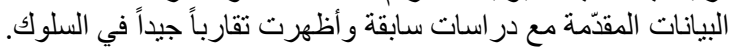

